\title{
Research on the Development of Non-governmental Science and Technology Awards of China: Environment, Problems and Countermeasures
}

\author{
Shaogang Liao, Yun Zhang, Jiansong Wei \\ School of Public Finance and Public Administration, Jiangxi University of Finance and Economics, Nanchang, China \\ Email address: \\ liaoshaogang@163.com (Shaogang Liao) \\ To cite this article: \\ Shaogang Liao, Yun Zhang, Jiansong Wei. Research on the Development of Non-governmental Science and Technology Awards of China: \\ Environment, Problems and Countermeasures. International Journal of Economics, Finance and Management Sciences. \\ Vol. 4, No. 1, 2016, pp. 1-9. doi: 10.11648/j.ijefm.20160401.11
}

\begin{abstract}
On the basis of the research on the development of Chinese non-governmental Science and Technology awards, we found that the non-governmental science and technology awards also have the disadvantages such as imperfect legislation, strong independence, low social recognition and management and so on. It needs to develop the legal system and improve the standardization of management.
\end{abstract}

Keywords: Non-governmental Science and Technology Awards, Incentive Mechanism, Development Status, Countermeasures

\section{Introduction}

Science and technology awards are the recognition method of the system, which is an important means of promoting the innovation of science and technology workers. Multi level, multi channel technology incentives provide a good platform for the innovation of different levels and aspects. The so-called non-government science and technology award, also known as folk Awards of science and technology and social forces, is relative to the government science and technology award. Scientific and technological award established by the scientific community social groups, enterprises, institutions (except state organs), individuals, etc.The authority and social influence of the non-governmental scientific and Technological Awards in China is not strong, it's brand construction lags behind, and their attraction and motivition for scientific and technological talents is limited. To a certain extent, it affects the role of non-governmental scientific and technological award for the scientific community and the development of science and technology. Therefore, the research and analysis of the development of China's non-government science and technology awards, the development status, explore effective measures to improve China's non government scientific and technological incentives to promote the development of non governmental scientific and technological incentives, and effectively play its role in the development of science and technology talents and scientific and technological development, and thus the implementation of innovation driven development strategy and the construction of innovative countries and services are very important.

\section{Development Environment Analysis of Chinese Non-governmental Scientific and Technological Award}

\subsection{The Internal Power of the Development of Chinese Non-governmental Scientific and Technological Award}

In twentieth Century 70-80's, almost all the national scientific and technological award is governmental awards, such as National Natural Science Award, the State Technological Invention Award, the National Science and Technology Progress Award and some of the governmental recognition of the occasional. Government science and technology awards can fully mobilize the enthusiasm and creativity of the Scientific and technical personnel.It also accelerate the development of science and technology and promote the construction of social spiritual civilization and material civilization.But from the point of view of the function of the scientific and technological award system, there are 
some flaws in the governmental science and technology awards in China.For example, the object of government award is a single outcome (specific outstanding scientific research projects)rather than a cumulative outcome (Specific individual scientists). So there is a selective error when the award is awarded, for example, the winners did not receive the award, the award of high grade but received a lower level of incentives, which affect the function of scientific and technological awards. The single government scientific and technological award system in China does not accord with the development trend of the diversification of scientific and technological award. This system can not fully meet the needs of social economy and scientific and technological award development. In addition, the award that undertakes the special incentives is few.And these incentives lack of professionalism and content. In order to solve the problem of functional defects of Chinese scientific and technological award system. We need to set up a new incentive program to improve the type of scientific and technological award, which gives the rise and development of Chinese non-government award inject momentum. Therefore, the internal dynamics of development of Chinese non-governmental scientific and technological award is generated mainly from Chinese scientific and technological award system functions self-improvement requirements.

\subsection{The External Environment for the Development of Chinese Non-governmental Science and Technology Award}

The rise of non-governmental scientific and technological award is an important symbol of Chinese science technology award system that was further improved. It reflects the results of a variety of factors, including economic, political, social and scientific and technological factors, and reflects the prosperity of Chinese economy and the improvement of social civilization. And it also verify the results of the positive interaction between the technology development and the science and technology and the society.Since the reform and opening up, Chinese economic, social cultural and policy environment has become the main environmental factors that affect the development of non- governmental scientific and technological incentives.

(1) Economic environment

Talent and capital are key factors of technological development, if you want to carry out scientific and technological reward activities, you need to reward funds and professional management expertise. With the prosperity and development of Chinese economy, enterprises and individuals can control the increase of capital. With the channels of social donation funds continue to increase, it not only enrich the social science and technology awards fund, but also to protect the operation of the foundation of social rewards. And the development of the socialist market economy will inevitably lead to the diversification of Chinese science and technology award. The establishment of Chinese market economy has created the conditions for the development of economy, and the development of economy has strengthened the need for science and technology.At the same time, the development of the market economy makes Chinese economic structure showing a variety of characteristics, in order to adapt to this change, the main body of scientific and technological incentives should also be developed in the direction of diversification. In addition, the success of Chinese reform and opening-up policy also create the necessary conditions for the international community and individuals to establish social science and technology awards offering.

(2) Cultural Environment

First of all, with the rapid development of social economy, the scientific and technological awareness of the Chinese people is generally enhanced.the social circles of science and technology are generally valued. In order to promote young scientists to take up the task of technological development and innovation through science and technology awards, This background makes science and technology awards to generate greater social repercussions and good results, it is advantageous to achieve the purpose of its award set. secondly, with the improvement of modern social civilization, people are more and more eager to engage in public welfare undertakings, in the past ten years, Chinese various social activities are increasing, such as a variety of poverty relief, disaster relief, "Hope Project", to help the disabled, environmental protection and other activities.

And some people who have the consciousness of science and technology, or engaged in related to science and technology, and hope to participate in the activities of public welfare social groups, organizations, enterprises and individuals, will choose to set up a scientific and technological award as to participate in public welfare social activities. It can improve the participants' social prestige in this way, and contributing to the increase of social rewards.

Moreover, some enterprises and institutions and academic organizations in order to promote their own development, they hope to enhance their own awareness and influence through scientific and technological incentives. And they want to attract scientific and technological talents or promote scientific and technological achievements, such as enterprise groups, various social science and technology award, etc.. In addition, some domestic and overseas progressives hope to make contributions to the cause of Chinese development by setting up science, such as "science and technology awards He Liang; hori fund", etc.

(3) Policy environment

Chinese reform and opening up policy is comprehensive. It is very necessary to implement the Chinese reform and opening up policy in the field of science and technology reward by supporting and encouraging the non-governmental science and technology awards. Therefore in the field of science and technology, it is a progressive measure in line with Chinese reform and opening up policy by establishing private research institutions and civil science and technology awards. Folk Science and Technology Awards as a social welfare activitie, its existence for the interests of the various existing distribution relationship will not have an impact, so the state will support and encourage citizens to participate in scientific 
and technological award activities.

With the implementation of policy of the rule of law deepening, in the process of Chinese modernization, the government department more and more emphasize the role of regulation of policy and law in the social and economic development.As a special kind of social activity, the non-governmental reward is also influenced by the government policy and the national law. The Chinese government has always supported and encouraged the non-governmental science and technology award.

Eighth NPC Standing Committee adopted the "Scientific and Technological Progress Law" In 1993, It provides "domestic and foreign organizations or individuals can establish scientific and technological award funds. They can reward citizens or organizations that have made outstanding contributions to scientific and technological progress activities, which is affirming the non-governmental science and technology awards from a legal perspective. After the introduction of the National Scientific and technological award regulations, National Scientific and technological award regulations, provincial and ministerial science and Technology Award, social forces to set up scientific and Technological Award and other relevant laws and regulations, it provides support of policy and legislation for Chinese non-governmental science and technology award.

Because of the support and encouragement from the government, non-governmental science and technology awards have the development momentum and conditions. The rise of the non-governmental science and technology awards in China has become a historical necessity. The promulgation and implementation of "science and technology progress law" is just like a strong catalyst, which has greatly accelerated the development of non-government science and technology awards. More and more newly established non-government scientific and technological award appeared in the 90's, which every month have a number of new awards to set up. The development of non-governmental science and technology awards is in a prosperous state under the support of relevant policies and laws.

\section{The Analysis of Chinese Non-governmental Scientific and Technological Award Problem}

Basing on the collection of Chinese existing non-governmental scientific and technological awards 'basic data, using statistical analysis method can be multiple angles from the reward subject categories and scope of awards, award cycle, intensity of incentives, reward object of the division, combined with the distribution situation of the industry awards, comprehensive analysis summed up Chinese non-governmental scientific and technological awards with awards diversification and reward increasing influence, the intensity of incentives to dispersion and other characteristics.

\subsection{The Category of Chinese Non-governmental Awards for Science and Technology}

Chinese non-governmental scientific and technological awards have a wide range of classification and methods, which can be divided into different categories from different perspectives. The main basis of the division is as shown in figure 1 .

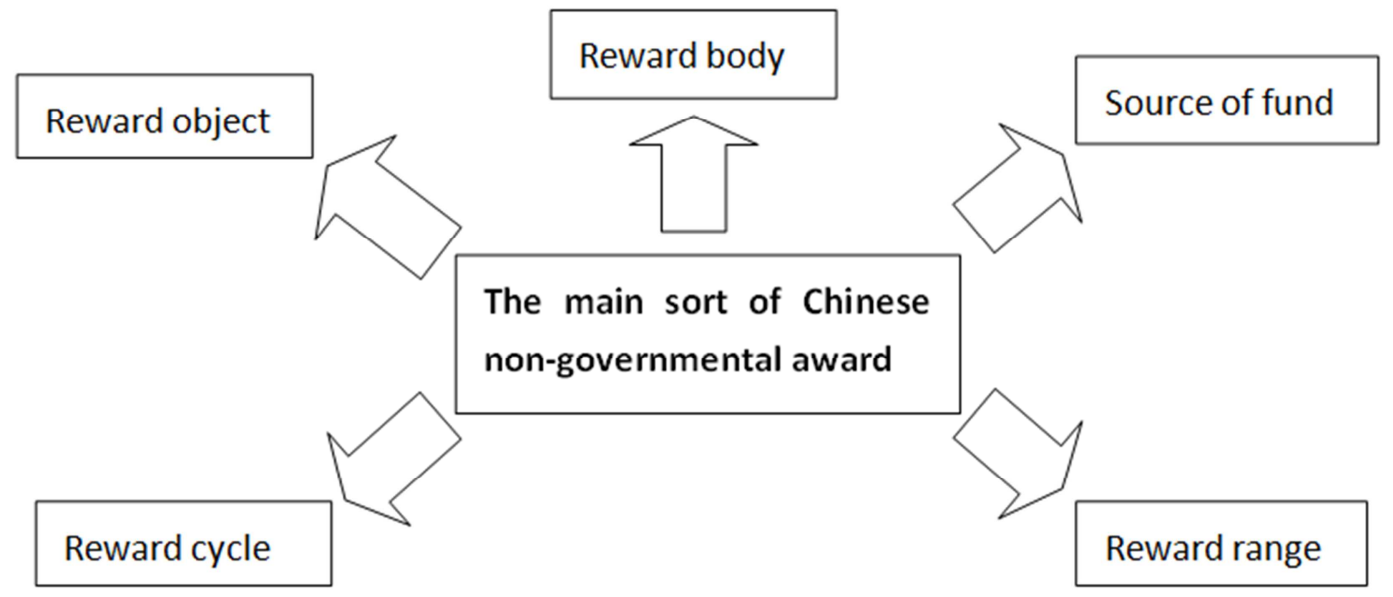

Figure 1. The main classification of Chinese non-governmental award.

According to different reward subject categories, Chinese non-governmental scientific and technological awards can be divided into these: (1) non-government scientific and technological awards founded by various academic groups, such as all levels of science and Technology Associations, associations, Chinese Academy of engineering; (2) non-governmental scientific and technological awards set up by foundation; (3) the non-governmental scientific and technological awards set up by enterprises and institutions; (4) non-governmental scientific and technological awards established by social groups, such as the Women's Federation, trade unions, the Communist Youth League and other mass organizations; (5) non-governmental scientific and technological awards set up by individual person.According to the awards of the main division, 265 non-governmental scientific and technological awards established with the 
consent of he national scientific and technological awards Office can be shown in table 1 shows.

Table 1. The number of non-governmental scientific and technological awards established by the state.

\begin{tabular}{llll}
\hline Number & The awards subject & Quantities & Percent \\
\hline 1 & Academic organization & 165 & $62.3 \%$ \\
2 & Foundation & 41 & $15.5 \%$ \\
3 & Enterprises and institutions & 34 & $12.8 \%$ \\
4 & Social groups & 15 & $5.7 \%$ \\
5 & Individual & 10 & $0.4 \%$ \\
\hline
\end{tabular}

According to different sources of funds, Chinese non-governmental scientific and technological awards can be divided into four types :the raise type, such as Li Siguang Geological Science Award, Zhan Tianyou Railway Scientific and Technological Award, the donative type, such as Deng Jiaxian, Yu Minhong scientific and technological award, He Liang $\mathrm{He}$ Li Foundation for scientific and Technological Award), the unit of its own funds type (such as Zhong Chuang software talent award, China Petrochemical Group Scientific and technological award, etc.) and the fundation funds interest type (such as Ulanhu Fund Award, Guangzhou High-tech Development Award, etc.).

In accordance with the scope of the award, Chinese non-governmental scientific and technological awards can be divided into comprehensive award, discipline award, industry award and special award. The comprehensive Award set for scientists who have outstanding contribution. There is no limit to the research field of scientists, such as Liang Heli fund science and technology award, Chinese youth Scientist Award, Chen Jiageng Science Award, etc.. Discipline Award is established of specific disciplines, such as the Hua Luogeng prize in mathematics, chemical science and technology award, the Chinese medical scientific and technological award. Industry Award set for specific industries, such as the China automotive industry science and technology progress award, China Petrochemical Group Science and technology award, the Li Siguang prize in science and technology. Special prize award has a strict award range, and the most characteristic award, such as the national science and technology entrepreneurs entrepreneurship award, a special reward make remarkable achievements of outstanding science and technology entrepreneurs in the promotion of technology achievements transformation and commercialization and industrialization.

In addition, it can also be divided into different classification according to the reward period and the object. According to the different period of the reward, Chinese non-government science and Technology Award can be divided into a period of one year, two years and three years, and so on. Among them, there are 114 non-governmental scientific and technological annual awards can be statistical like Chinese auto industry scientific and technological progress award, accounting for $43 \%$ of the total number of non-governmental scientific and technological awards; there are 90 awards award every 2 years include Li Siguang geology scientific award, accounting for $34 \%$ of the total number of non-governmental scientific and technological award; in addition, there are few rewards reward over a period of three years or more (such as five years period or rules changes or unknown statistics) of non-governmental scientific and technological awards, including Li Ao burnt medicine prize, a total of 61 , accounting for $23 \%$ of the total number of non-governmental scientific and technological awards. As shown in figure 2 .

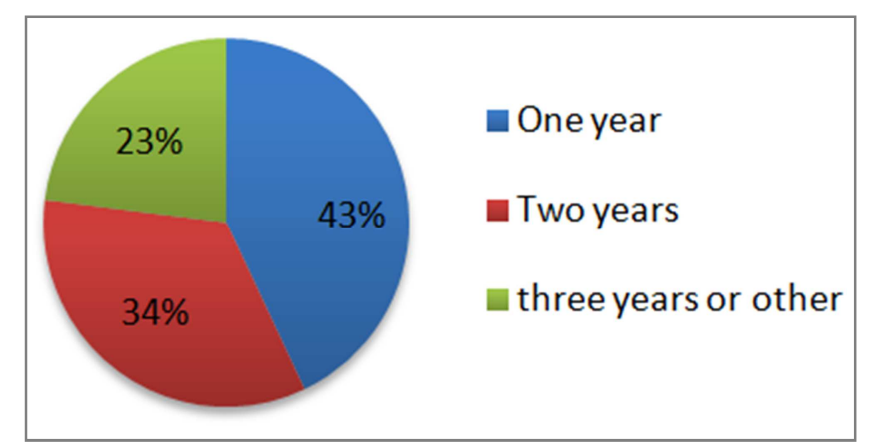

Figure 2. The pie chart of the reward cycle classification of the non-government science and technology award.

According to the different types of incentives for the object, Chinese non-government scientific and technological awards are divided into 3 categories:reward to people, reward to results and reward to achievements. According to the statistics, there are 103 awards belong to the first category like He Liang $\mathrm{He} \mathrm{Li}$ fund for science and technology award, accounting for 39\% of the total number of awards; and 100 awards belong to the second category including the metallurgical science and technology award, accounting for $38 \%$ of the total number of non-governmental awards; incentive object includes both people and results of the non-governmental awards including China's auto industry scientific and technological progress award, a total of 32 , accounting for $12 \%$ of the total number of non-governmental awards. In addition, there are 30 non-governmental scientific and technological awards are not included in the statistical range because of the lack of information. As shown in figure 3.

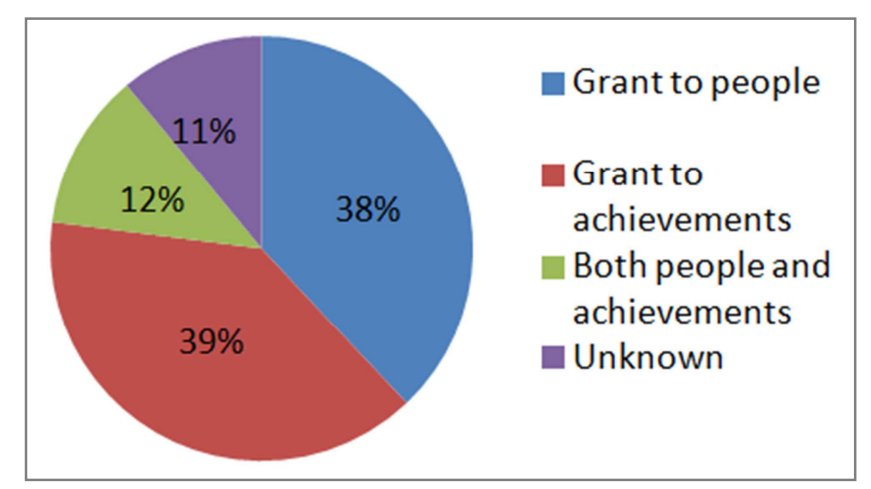

Figure 3. The pie chart of the award object of the non-government science and technology award. 


\subsection{The Main Problem That Restricting the Development of China's Non-governmental Scientific and Technological Award}

\subsubsection{The Number Is Less, and the Industry Distribution Is not Balanced}

Compared with developed countries, there is still a big gap in the number of non governmental scientific and technological awards in China. By the end of 2014, less than 500 non-governmental scientific and technological awards are agreed to registration by the Ministry of science and technology and provinces and cities, while the Association of United States chemical has set up 62 by the end of 2007. The lack non-governmental scientific and technological awards reduced the influence of non-governmental scientific and technological awards in the scientific community, also in a weak position when compared with the national award. This not only has a huge gap compared with the developed countries in the non government science and technology awards system, but also can not meet the state proposed to establish a government incentive oriented, the use of social forces and units and social forces for the main incentive system of talent, this talent policy. The lack of the number also led to the industry distribution of awards imbalance. A lot of Chinese non-governmental science and technology awards are industry awards and the reward objects generally only limited in the industry, which led to some industry awards, cross and repeat.On the other hand, some industry is the "vacuum", there is no award for them. Overall, Chinese non-governmental science and technology awards are widely distributed, but some industry have a number of awards, such as the pharmaceutical industry has more than 16 awards include the Chinese medical science and technology award, ; while some industry has only 1 award or nothing, such as leather, footwear and other industries. According to the statistics, awards concentrated on several industries like electric power, petroleum, chemical industry, medicine, construction, transportation and other six industries. These industries occupy more than $25 \%$ of all the non-government science and technology awards, while award distribution least industry mainly in the field of social science, only the Wang Xuan news science and technology award, China Science Writers Association Award for outstanding works of popular science, science and technology of China law society science and technology law award can be found in this industry, a coverage rate lower than $1 \%$.

\subsubsection{The Legislative Level Is Low, and the System of Laws and Regulations Is not Perfect}

The legislative of Chinese non-governmental scientific and technological award is mainly related to the regulation of governmental scientific and technological award law, which makes it has the following drawbacks: first, the existing law of the non-government scientific and technological award is in a low level. At present, the National Science and Technology Award Regulations and the Regulation of Social to Set Up the Scientific and Technological Awards are the only two policy and regulations relate to the non-governmental scientific and technological award.But the former is the administrative regulations, and the latter is the department regulations, both have not risen to the legal level. This is not compatible with the important role it plays in the development of science and technology in China, so how to improve the level of non-governmental scientific and technological award has become a priority. Second, the lack of legal norms of the non-governmental science and technology award of specific incentives. Under the existing system, many of the provisions of the regulations of the non-governmental scientific and technological award of the specific application conditions are not clear; the same technology can not declare the same level of incentives to make provisions. In the practice of non-governmental scientific and technological incentives, the same result can be found everywhere, which is a huge waste of the limited resources of the non-governmental science and technology. Third, China lacks the punitive regulations on non-governmental scientific and technological awards. Seeing from the existing regulations about non-governmental science and technology award, we'll find that penalties stipulated are rarely, and the provisions are very vague, no clear legal responsibility is told about illegal behavior. Fourth, the part of the legal responsibility of the non-governmental scientific and Technological Awards is too simple, which make it hard to curb the illegal behavior of the non-governmental scientific and technological awards. There's no clear stipulation of the type and scope of punishment of non-governmental science and technology award,which make the administrative penalty or punishment of law enforcement is not clearly or abuse of power; the second is the subject of law enforcement is not clear, if you think the subject of administrative law enforcement is administrative department of science and technology, then the administrative punishment is easy to understand, but administrative punishment is difficult to interpret,.the science and technology administrative authority is difficult to give the people who set non-governmental science and technology award a disciplinary,if the people are not attach to the authority.

\subsubsection{Lack of Independence, and Semi-official Characteristic}

Among Chinese currently running 265 non-governmental scientific and technological awards, most of them are not independence with semi-official characteristic, because the organizations that set up the award have a complicated relationship with government departments. The industry association and the society have most awards, accounting for nearly half of the proportion in non-governmental scientific and technological awards.These associations and societies belong to the Ministry of civil affairs registration and management of social organizations, while social groups in China often with semi-official characteristic. Because national social organizations department is in charge of the relevant departments of the State Council and its authorized organization, Social groups attached to the department in charge of the business, anchored in the government sector.Many associations and societies use administrative 
establishment,and financial allocated by the state. What's more, National Science and technology reward system reformed 1999, the provincial and ministerial level scientific and technological award were greatly streamlined, those abolished ministerial level scientific and technological award mostly continued in the form of industry association and the society for scientific and technological award, shifted to the non-governmental awards. Some associations also perform industry management functions, a lot of industry associations, the Institute of science and technology awards were changed from the government science and technology award. Some other awards units, like Chinese Academy of Sciences, Academy of engineering, post office and others belong to the institutions directly attach to the State Council.China Federation of trade unions, the Communist Youth League, China Association for science and technology are the special status of the organizations of the masses, in a great extent performed the functions of the government; dozen of awards enterprises are large state-owned enterprises, accounted for the vast majority.Since these awards agencies accept the guidance and support of government departments, their awards have a quasi official nature, their ideas award setting and appraisal method may be affected by the Department they attach to,and that make them lack of independen.ce and characteristic.

\subsubsection{Chinese Government Scientific and Technological Award System Has not Been Layered, and the Derived Treatment Problem Is Ambiguous}

The social stratification standard of Chinese governmental scientific and technological award system is based on the administrative level of the subject. Governmental scientific and technological award are divided into two levels: national level and provincial and ministerial level. While the non-governmental scientific and technological award does not exist the basis of administrative power, so it does not exist the possibility of hierarchical. Therefore, the social stratification of the non-governmental scientific and technological award is more complex, and there is no consensus in the academic community. Thus, a series of problems have been produced, which are manifested in the two aspects of "social recognition" and "derivative". Because there is no level, various awards don't have a exactly location of which level of award of science and technology the belong to. Scientific and technical personnel also lost the enthusiasm because of the award that admit the prize level low or not be united. And in the formation of Chinese long-term "officer better than people" mode, social always divide different level according to administrative levels and recognized by the reward level. Awards with low level are often difficult to be recognized by the society. Therefore, the non-governmental awards is to comparable with the government awards. Although some non-governmental awards such as Dan Ping Wang Science Award, HLHL fund for science and technology award, from the point of view of the scientific community, are very high level awards. But it is difficult to get approval from the government, even in the science and technology statistics, because there is no so-called administrative authority. And the awards were not admitted that the unit determines the derivative treatment, level award level determines the amount of derivative treatment. Therefore, the high visibility of the non-governmental awards also derived a series of treatment, but the low visibilities of the non-governmental awards don't even sheets who admitted to. There is no any derived treatment any more.

At present, Chinese non-governmental scientific and technological awards have not set up a complete management forms. First, it performances in the application of the assessment process is unreasonable. The prestige of any award, and the ability to ensure the fairness and accuracy of the reward to achieve the desired results, depend on the establishment of a strict reporting and assessment procedures. Chinese non-governmental scientific and technological award is easy in the declaration process and review procedure. Even in the process of reward was mixed with subjective will; this will inevitably impact the authority and impartiality of the award. Followed by non-governmental scientific and technological awards are owed both at home and abroad social forces, not what the government does, the bonus is raised by social organizations, enterprises, institutions or individuals funded,instead of financial allocation.Also the operation is handled by social forces themselves with very large autonomy, which makes it optional in the reward object, the reward standard, and program evaluation.Most awards set in China has a good original intention, but management and guidance system of Chinese non-governmental scientific and technological awards is not systematic, and some non-governmental awards were set up blindness and operation lack of normative, which makes some awards deceptive, even affect the non-governmental awards social reputation.

\section{Countermeasures to the Development of Non-governmental Scientific and Technological Award in China}

The development of Chinese non-governmental scientific and technological award is inseparable from its legalization of structural system and standardization of the management mode. To truly achieve the institutionalization, sequencing, quantification and standardization of development and operation of non-governmental scientific and technological award is an important guarantee to realize the non-governmental scientific and technological awards.

\subsection{To Ensure the Legalization of the Development of Non-governmental Scientific and Technological Award}

\subsubsection{To Speed up Enactment of "The Non-Governmental Scientific and Technological Award Law" and to Improve the Legislative Level}

It is very necessary to speed up the enactment of The Non-Governmental Scientific and technological award Law and to improve the legislative level. According to the 
scientific and legislative principles, the enactment should process some attributes of advancement and also should choose the best legislative form, content and the best drafters for the law as far as possible.

The role of non-governmental scientific and technological award in the development of national science and technology is increasingly remarkable. Owing to administrative regulations promulgated by the State Council are no longer suitable as regulations to adjust the legislative form of non-governmental scientific and technological awards, it should improve from the legislative level and be adjusted by the law.

The reasons are as follows. In the practice of Chinese legislation, the regulations of the scientific and technological award in every province and municipality and the means of the non-governmental scientific and technological award are coexisting.

If it is regulated that the non-governmental scientific and technological award should be merged into the regulations of the national scientific and technological award, according to the principle that is the upper law guides the lower law, all the regulations of the scientific and technological award in every province and municipality and of the non-governmental scientific and technological award will be required to reconstruct.

This approach will result in high cost of legislation, and also violate the economic principles. To sum up, enactment of "The Non-Governmental Scientific and technological award Law" is the main measure to achieve legalization and institutionalization of the development of non-governmental scientific and technological award.

\subsubsection{To Reasonably Arrange the Content of Legislation, and Establish a Fair and Rational Mechanism of Award and Punishment}

Firstly, there should be specially dedicated a chapter on award and punishment in non-governmental scientific and technological award, which can summarize the experience in previous legislation. If it is necessary to set the rules in practical work, stipulations should be promulgated in the law as soon as possible. If in the original administrative regulations there are stipulations related to the punishment which is not incomplete or too general and also on the basis of "The Non-Governmental Scientific and technological award Law", the relevant stipulations should be added. If the contents of the original administrative regulations are outdated, stipulations should be re-stipulated in the new law.

Secondly, it is obliged to change the hardening practices in the previous Scientific and Technological Award Law, namely, prohibited acts shall stipulate clearly. The stipulations are not promulgated straightly, but focus on making requests from the affirmative aspect. Practice has proven that stipulating what should do is helpless to prevent the illegal acts, due to the stipulations are just stay at drawing a clear boundaries between legal and illegal legislation.

Thirdly, it shall establish a penalty system based on finance. An important purpose of non-governmental scientific and technological award is to promote scientific and technological work to enter into the main battlefield of Chinese economic construction as soon as possible. A large increasing of economic activities leads to economic legal relations as the leading role in a large number of scientific and technological legal relations. This change results in illegal acts related to economic content as the main illegal form in the field of the non-government scientific and technological award.

Experience has shown that the illegal behaviors in economic activities just punished by the administrative punishment or the criminal punishment are impractical. It must suit the remedy to the case, and use the economic means to hit. The increasing use of the finance punishment is the effective method is to cope with economic crimes, crimes of hindering social management order including crimes committed by unit. Criminals seeking illegal economic interest punished by the deprivation of money can make them not only gain little money but also lose the capital of the crime.

\subsubsection{To Improve the Legal Norms of Operating Mechanism in the Non-governmental Scientific and Technological Award}

On the condition that the "non-government scientific and technological award law" still have not set up, every units who creating the non-government scientific and technological award should carry out awarding activities strictly according to management method of social support award of science and technology.

when institutions and individuals intend to set up a new non-government scientific and technological award, the applicant shall submit to the registration authority (National Scientific and Technological Department) a series of materials, including: application report; incentives or draft articles of Association; the basic information and certifications of the person who set up the award; contractors and the information of the person in charge of the case; documents; the information about the review members; certificate of office use right; and the source of reward funds; other materials required by the registration management organization.

In this process, the applicant should submit the application materials to the registration management authority and reflect the real situation, and also should be responsible for the authenticity of the substance of the application materials.

National Scientific and Technological Department is responsible for the registration of non-government scientific and technological award, all the applications are accepted in an unified way by the National Scientific and Technological Award Work Office.

The administrative department of science and technology in every province and municipality can ascertain the accepting institution and the accepting method toward the applicant of social support award in the field of the local administration according to management method of social support award of science and technology. 


\subsection{To Improve Standardized Measures of the Non-governmental Scientific and Technological Award for the Development}

\subsubsection{To Carry out Management Mode of Quality Management System}

In the new period, China put forward the strategy of "building an innovative country". As the strategy of national science and technology innovation propelling, it is bound to put forward objectively higher requirements to the work of many non-governmental scientific and technological reward management. In order to adapt to this situation, management mode of the unit who creating the non-government scientific and technological award should be better standardize and it is necessary to find a more scientific and reasonable management mode. ISO9000 standard for scientific and technological award provides a successful management model. The quality management system established according to the ISO9000 standard. From the process of identification, the establishment of the goal to management responsibilities, product realization and continuous improvement, all the activities of quality management system are ascertained by the document and the records are as evidence.

Therefore, all the units are bound to form a documentation system in the work of science and technology award. These make management in the work of scientific and technological award more standardized, procedural, and documenting.

\subsubsection{To Increase the Transparency of the Reward Activities}

At present, when most of the non-governmental scientific and technological award announces the winning project which is just including the project name and project personnel, it is very difficult for others to gain the specific information about the award. In order to regulate the awarding behavior, the awarding unit should increase the transparency (such as the announcement of the project introduction, innovation point, contribution rate to the development of science and technology, etc.). By doing this can fully achieve the function of social supervision. If appropriate, it is necessary to explain the reason of winning or losing the award. This can make the applicants know the reason. In the selection of judges, as well as the discussion, scoring, voting of judges, it is necessary to reduce the transparency in order to avoid the interference of the outside world, so that judges can independently judge with no hesitation. The methods such as expert database establishment, double blind method and single blind method, can be adopted.

\subsubsection{To Improve the Recommendation Mechanism of Award}

In order to reflect the academic value of the applicant and the fairness of the award, every unit should standardize their award mechanism and carry out the mechanism of nomination. The merit of the nomination mechanism is nominated by the leading experts in the academic world. They work at the frontier of science and technology. They are familiar with the candidates who have made new achievements. They often hold very prudent attitude to the candidates. At the same time, the nomination is "back to back", therefore, it is the defense line of the insurance of the fairness. The nomination mechanism also reflects the full trust of the academic level and the moral level of the nominators.

\subsubsection{Reform and Simplify the Review Process and Standardize the Review Process}

Reporting and review procedures of some Chinese non-governmental scientific and technological award are cumbersome and complicated. This has seriously affected the applicants' enthusiasm and work of reviewing to carry out smoothly. Although the tedious process of the evaluation in some extent maintain the seriousness and authority of the assessment, the increasing of the number of the process or the link also make the interference source of scientific and technological award assessment increased, so as to influence the stability and standardization of the assessment work.

Therefore, it is necessary to reduce the evaluation link, and to simplify the review process. In the case of the good conditions, it can also appropriately add review mode of the non-objection system. By doing so, not only can reduce interference of the evaluation system, but also can lower the cost of reporting and reviewing, to improve the efficiency of the assessment, so that the assessment work can really be simple but not disordered, standardized and efficient.

\section{Conclusion}

The development of non-governmental Science and Technology Awards has important practical significance for the construction of a diversified science and technology award system, which is to encourage the majority of scientific and technological workers and improve the system of science and technology award. On the basis of deepening the reform of science and technology development, Chinese Science and Technology Award regulatory agencies and the scientific community need from the status quo of implimention of Chinese Science and Technology Award. They should study the development momentum, status and problems of non-governmental science and technology award, and analyze the internal and external factors that restrict the healthy development of China's non-governmental science and technology award. They should regulate the establishment and operation of non-governmental science and technology award from the system construction, management mechanism and the development of the model. The development and expansion of the non-governmental science and technology award not only need to effective institutional arrangements and policy support of management, but also need scientific community recognition and support. Of course, Public acceptance and recognition is also very important. Therefore, to promote the development of non-governmental science and technology awards government that need society, individual citizens, and multiple forces work together. 


\section{References}

[1] Wang Yankun, Zhong Shuhua et al. [M]. Wuhan: China University of science and Technology Press, 2000: 190-214.

[2] Wang Yankun, Zhong Shuhua. Beijing: People's publishing house, 2007.

[3] Wang Yankun, Zhong Shuhua. The cause of the rise of Chinese folk scientific and technological award and its mechanism [J]. science research, 1996, 14 (2): 58-61.

[4] Heyan. China on coke folk scientific and technological award and the national science and technology awards between [J]. Chinese science and technology award, 2004, (1).

[5] Zhao Dongwei. The direct system analysis of the scientific and technological award [D], 2006.

[6] Chen Haidong. The status quo and characteristics of China's social forces to set up the scientific and technological award [J]. China Science and technology award, 2007 (3): 73-75.

[7] Zhang Taowei, Ning Guodong. [J]. technology and innovation management, 2008 (3) of the legal system of science and technology awards in China.

[8] Jiang Jingnan, Yin Bangqi et al. Social forces to set up the scientific and technological award to explore the [J]. industrial technology economy, 27, 2008 (5).

[9] Wan Qiang Xu, Xiong Xiao Gang. The current situation of the development of Chinese non-governmental science and technology awards, causes and trends $[\mathrm{J}]$. China Science and Technology Forum. 2010, (06).

[10] China Association for science and technology "National Science and technology reward system in the non-governmental awards research group, and vigorously strengthen non-governmental science and technology awards brand construction [J]. Science Herald, 2011, 29 (05).

[11] Xu Wan-qiang, Xiong Xiao-gang. Disparities and countermeasures on the non-governmental science and technology awards between china and developed countries. Studies in science of science. 2010. 